9 - ORIGINAL ARTICLE

ISCHEMIA-REPERFUSION

\title{
Effect of Otostegia persica extract on ischemia/reperfusion induced renal damage in diabetic rats. A biochemical study ${ }^{1}$
}

\author{
Mohammad Ashrafzadeh Takhtfooladi ${ }^{I}$, Ahmad AsghariI ${ }^{\text {, Hesam aldin Hoseinzadeh }}{ }^{\text {III }}$, Farahnaz Mokhtari ${ }^{\text {IV }}$ \\ DOI: http://dx.doi.org/10.1590/S0102-865020160060000009 \\ IPhD, Young Researchers and Elites Club, Science and Research Branch, Islamic Azad University, Tehran, Iran. Conception and design of the study; \\ acquisition of data, manuscript writing.

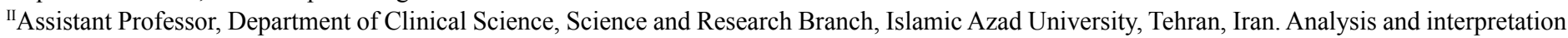 \\ of data, supervised all phases of the study.

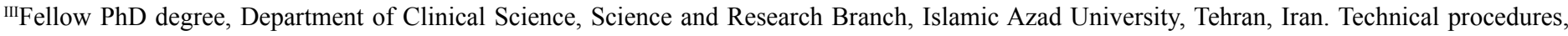 \\ analysis and interpretation of data. \\ ${ }^{\mathrm{IV}}$ Graduate student, Veterinary Medicine, Science and Research Branch, Islamic Azad University, Tehran, Iran. Technical procedures, acquisition and \\ interpretation of data.
}

\section{ABSTRACT}

PURPOSE: To evaluate the effect of Otostegia persica (O. persica) extract on renal damage induced by ischemia/reperfusion (I/R) in diabetic rats.

METHODS: Forty-eight rats were subjected to right nephrectomy; then, they were allocated into six groups: Sham; Diabetic sham; I/R; Diabetic I/R; I/R+O. persica; Diabetic I/R+O. persica. Diabetes was induced by streptozotocin (200 mg/kg, i.p.). O. persica (300 mg/ $\mathrm{kg} /$ day, p.o) was administered for 2 weeks. On the 15th day, ischemia was induced in left kidney for 60 min, followed by reperfusion for $24 \mathrm{~h}$. Renal functional and biochemical markers were estimated.

RESULTS: $\mathrm{I} / \mathrm{R}$ in both normal and diabetic rats, induced a significant elevation in serum levels of urea and creatinine $(\mathrm{p}<0.05$ ). Renal $\mathrm{I} / \mathrm{R}$ induced a significant increase of malondialdehyde, myeloperoxidase and nitric oxide concentrations associated with significant reduction in superoxide dismutase and catalase activities in comparison with the sham group $(\mathrm{p}<0.05)$. Diabetic rats that underwent renal $\mathrm{I} / \mathrm{R}$ exhibited a significant increase in all the studied parameters with a reduction in the antioxidant enzymes as compared to nondiabetic rats $(\mathrm{p}<0.05)$. These deleterious effects associated with renal I/R were improved by the treatment with $O$. persica $(\mathrm{p}<0.05)$. CONCLUSION: Otostegia persica pretreatment protected the renal injury from ischemia-reperfusion in diabetic rats. Key words: Diabetes Mellitus. Ischemia. Reperfusion. Oxidative Stress. Rats. 


\section{Introduction}

Diabetes mellitus, causes organ dysfunction and increases the sensitivity of organs to damages ${ }^{1}$. Moreover, ischemic insults are often recurrent in diabetic patients. In the setting of loss of renal blood flow autoregulation that characterizes the post ischemic kidney, renal ischemia/reperfusion (I/R) injury is a major cause of acute renal failure. Diabetic patients may need renal transplantation in their later life due to diabetic nephropathy and $\mathrm{I} / \mathrm{R}$ injury is one of the dangerous complications of this procedure 2 .

Renal I/R causes tissue injury via oxygen radicals and oxidative stress caused by an imbalance in the production of reactive oxygen species (ROS) and antioxidant capacity ${ }^{3}$. ROS and nitric oxide (NO) play an important role in mediating cell damage during $\mathrm{I} / \mathrm{R}$ injury ${ }^{4}$. Inflammation contributes substantially to the pathogenesis of $\mathrm{I} / \mathrm{R}$ with a central role for particular cells, adhesion molecules, and cytokines ${ }^{5}$. Neutrophils are the inflammatory cells that produce high levels of ROS during I/R injury. Myeloperoxidase (MPO) is found in neutrophils and is found to catalyze the formation of hypochlorous acid, a toxic agent to cellular components, which initiates oxidative injury ${ }^{6}$. Antioxidants are of interest to biologists and clinicians because they help to protect the bodies of human and animals against damages induced by ROS generated in some diseases and even in aging process. There are many evidences that natural products and their derivatives have efficient antioxidative characteristics, consequently linked to antidiabetic, anti-aging and anti-inflammatory activities ${ }^{7,8}$.

Otostegia persica is an endemic plant that can be found in south and southeastern provinces of Iran. In Iranian traditional medicine the $O$. persica extract is used as an antihistamine, antispasmotic, antiarthritis and antidiabetic ${ }^{9}$. The antioxidant activity of the different extracts and fractions of aerial parts of $O$. persica has been evaluated ${ }^{10}$. Recent studies on aerial parts of this plants suggested $O$. persica could be considered as medicinal herbal candidate for treatment of diabetes ${ }^{11}$. The present study was investigated to study the antioxidant activity and antidiabetic effect of $O$. persica extract on IR injury in the kidney of the diabetic rats.

\section{Methods}

The care and handling of the animals were in accordance with the guidelines of the Islamic Azad University College of Veterinary Sciences, Animal Care and Use Local Ethics Committee.

Forty-eight $(\mathrm{n}=48)$ adult male Wistar rats weighing $300 \pm$ $20 \mathrm{~g}$ were used in this study. They were purchased from the Pasteur
Institute of Iran, and allowed free access to standard commercial rodent chow pellets and filtered tap water ad libitum. They were kept under constant conditions at a temperature of $22 \pm 2{ }^{\circ} \mathrm{C}$ with a 12-h dark/light cycle for one week before the start of the study.

All rats were subjected to right nephrectomy; then, they were randomly allocated into six groups each consisting of eight animals:

Group 1: Sham: non-diabetic rats were used as normal control group.

Group 2: Diabetic sham: diabetic rats were used as diabetic control group.

Group 3: I/R: non-diabetic rats were subjected to $I / R$.

Group 4: Diabetic I/R: diabetic rats were subjected to $\mathrm{I} / \mathrm{R}$.

Group 5: $\mathrm{I} / \mathrm{R}+O$. persica: rats received $O$. persica $(300$ $\mathrm{mg} / \mathrm{kg}$ ) orally daily for 2 weeks; then, they were subjected to I/R.

Group 6: Diabetic $\mathrm{I} / \mathrm{R}+O$. persica: diabetic rats received O. persica $(300 \mathrm{mg} / \mathrm{kg})$ orally daily for 2 weeks; then, they were subjected to $\mathrm{I} / \mathrm{R}$.

\section{Preparation of $O$. persica extract}

The $O$. persica was collected from southern of Iran. The plant was identified by the Department of Botany of the Islamic Azad University. The aerial parts of $O$. persica were powdered in a mill. $500 \mathrm{~g}$ of sample was selected and raised the volume to $1 \mathrm{~L}$ by ethanol $(96 \%)$. The solution percolated after $48 \mathrm{~h}$, then the solvent was removed under reduced pressure at low temperature and finally about $10 \mathrm{~g}$ concentrated extract was prepared. Doses of the extract were prepared using normal saline ${ }^{12}$.

\section{Experimental induction of diabetes in rats}

Diabetes was induced by a single injection of streptozotocin (200 mg/kg, i.p.) in overnight fasting rats. Streptozotocin was dissolved in citrate buffer $(\mathrm{pH} 4.5)$ and nicotinamide was dissolved in normal saline. After 7 days, blood was collected and serum samples were analyzed for blood glucose $^{13}$. Animals showing fasting blood glucose higher than 250 $\mathrm{mg} / \mathrm{dL}$ were considered as diabetic and used for the study.

\section{Experimental protocol}

Right nephrectomy was performed through a right flank incision $(2 \mathrm{~cm}$ ) under general anesthesia (ketamine and xylazine, $50 \mathrm{mg} / \mathrm{kg}$ and $10 \mathrm{mg} / \mathrm{kg}$, i.m., respectively). After right 
nephrectomy, treatment was given as mentioned previously for 2 weeks. On day 15, ischemia was produced in the left kidney by performing a left flank incision and dissecting the left renal pedicle to expose the renal vessels. Non traumatic vascular clamps were used to stop blood flow (in artery and vein) for $45 \mathrm{~min}$. Reperfusion was established by removing the clamp. The surgical site (muscular layer and skin) was closed with 4.0 mononylon suture. Body temperature was maintained at $37 \pm 0.5{ }^{\circ} \mathrm{C}$ with a heating pad and monitored using a rectal thermometer. At the end of reperfusion period $(24 \mathrm{~h})$, blood samples were collected and used for the estimation of renal function (serum creatinine and urea). The abdomen was opened, and the kidney was harvested for the biomarkers of oxidative stress.

\section{Determination of serum creatinine and urea levels}

The blood samples were allowed to clot for $10 \mathrm{~min}$ at room temperature. Clots were centrifuged at $2500 \mathrm{rpm}$ for 10 min to separate the serum and submitted for evaluation of serum creatinine and urea levels. Creatinine and urea concentrations of serum were measured spectrophotometrically by using commercial kits by Automatic DADE Analyzer ${ }^{\mathrm{TM}}$.

\section{Preparation of tissue homogenates}

The renal tissue was homogenized in $10 \mathrm{mM}$ Tris- $\mathrm{HCl}$ buffer, $\mathrm{pH} 7.4(10 \% \mathrm{w} / \mathrm{v})$ with 25 strokes of a tight Teflon pestle of a glass homogenizer at a speed of $2500 \mathrm{rpm}$. The clear supernatant was used for assays of lipid peroxidation (malondialdehyde (MDA) content), MPO activity, NO level and endogenous antioxidant enzymes like, superoxide dismutase (SOD) and catalase (CAT).

\section{Biochemical study}

Lipid peroxides in kidney tissues were determined spectrophotometrically as thiobarbituric acid reactive substances according to the method of Preuss et al. ${ }^{14}$. Tissue lipid peroxide levels were expressed as nanomoles of MDA formed per gram tissue weight. The activity of SOD was assessed as described by Marklund $^{15}$. The SOD activity was expressed as units per mg tissue protein. The CAT activity was measured according to Aebi ${ }^{16}$. The results were expressed as U/mg. The NO was estimated by the method of Lepoivre et al. ${ }^{17}$. The amount of NO present in the samples was estimated from the standard curves obtained. The standard curve was prepared by using sodium nitrite solutions with concentrations in the range of $1-100 \mu \mathrm{M}$ by diluting the nitrite standard solution. The MPO activity was measured in tissues by a procedure similar to that previously documented by Hillegas et $a l .{ }^{18}$. One unit of enzyme activity was defined as the amount of MPO present that caused a change in the absorbance measured at $460 \mathrm{~nm}$ for $3 \mathrm{~min}$. The MPO activity was expressed as U/g of tissue.

\section{Statistical analysis}

Results were expressed as Mean \pm standard deviation. Results were analyzed using the Statistical Package for the Social Sciences, version 18. One-way analysis of variance (ANOVA) followed by Bonferroni's post-hoc test were used to test the significance of the difference between quantitative variables. Differences were considered significant at $p$ values less than 0.05 .

\section{Results}

Reperfusion of ischemic kidney in both normal and diabetic rats, induced a significant elevation in serum levels of urea and creatinine $(\mathrm{p}<0.05)$ compared with sham group (Table 1). The results of this study indicated a significant increase of the glycemia in diabetic rats with no further increase in the blood glucose by renal I/R injury. However, the extract of $\mathrm{O}$. persica significantly decreased blood glucose levels when compared with diabetic rats (Table 1).

TABLE 1 - Renal function tests of the groups.

\begin{tabular}{cccc}
\hline Groups & Urea & Creatinine & Glucose \\
\hline Sham & $28.8 \pm 4.1$ & $1.02 \pm 0.06$ & $93.5 \pm 7.9$ \\
Diabetic sham & $40.1 \pm 5.7$ & $1.19 \pm 0.04$ & $381.2 \pm 6.1^{* * * \# \#}$ \\
I/R & $43.7 \pm 6.9^{*}$ & $1.41 \pm 0.09^{*}$ & $116.3 \pm 6.6$ \\
Diabetic I/R & $67.6 \pm 8.4^{\dagger}$ & $2.32 \pm 0.2^{\dagger}$ & $378.6 \pm 9.4^{* * * \# \#}$ \\
I/R+ O. persica & $32.7 \pm 3.5$ & $1.22 \pm 0.09$ & $119.5 \pm 11.2^{\dagger \dagger}$ \\
Diabetic I/R+ & $36.1 \pm 3.0$ & $1.32 \pm 0.11$ & $147.2 \pm 13.6^{\dagger \dagger}$ \\
O. persica & & & \\
\hline
\end{tabular}

*Significantly different from sham and $\mathrm{I} / \mathrm{R}+O$. persica groups at $\mathrm{p}<0.05$; 'Significantly different from Diabetic sham and Diabetic $\mathrm{I} / \mathrm{R}+O$. persica groups at $\mathrm{p}<0.05$;

***Significantly different from sham group at $\mathrm{p}<0.001$;

"\#" Significantly different from I/R group at $\mathrm{p}<0.001$;

\#Significantly different from Diabetic IR group at $\mathrm{p}<0.001$.

Additionally, Table 2 showed that renal I/R induced oxidative stress in both normal and diabetic kidneys in the form of a significant increase $(p<0.05)$ of MDA, MPO and NO concentrations associated with significant $(\mathrm{p}<0.05)$ reduction in 
SOD and CAT activities in comparison with the sham group (Table 2). Diabetic rats that underwent renal $I / R$ exhibited a significant increase in all the studied parameters with a reduction in the antioxidant enzymes as compared to nondiabetic rats $(p<0.05)$, suggesting a significant degree of kidney dysfunction caused by renal $\mathrm{I} / \mathrm{R}$ in diabetes. These deleterious effects associated with renal $\mathrm{I} / \mathrm{R}$ were improved by the treatment with $O$. persica in comparison with diabetic I/R group $(\mathrm{p}<0.05)$.

TABLE 2 - Renal tissue oxidative stress activities of the groups.

\begin{tabular}{cccccc}
\hline Groups & MDA & MPO & NO & SOD & CAT \\
\hline Sham & $95.85 \pm 6.49$ & $0.71 \pm 0.03$ & $0.61 \pm 0.03$ & $69.39 \pm 7.69$ & $9.97 \pm 0.72$ \\
Diabetic sham & $115.57 \pm 11.7$ & $1.65 \pm 0.09$ & $0.74 \pm 0.06$ & $53.28 \pm 8.72$ & $8.52 \pm 1.13$ \\
I/R & $127.89 \pm 6.45^{*}$ & $5.81 \pm 0.21^{*}$ & $1.22 \pm 0.09^{*}$ & $48.55 \pm 5.98^{*}$ & $7.19 \pm 0.81^{*}$ \\
Diabetic I/R & $164.54 \pm 9.3^{\dagger}$ & $7.39 \pm 0.22^{\dagger}$ & $1.57 \pm 0.11^{\dagger}$ & $33.76 \pm 5.66^{\dagger}$ & $4.22 \pm 0.5^{\dagger}$ \\
I/R+ $\boldsymbol{O}$. persica & $102.91 \pm 7.75$ & $0.95 \pm 0.09$ & $0.91 \pm 0.08$ & $63.09 \pm 7.17$ & $9.21 \pm 0.81$ \\
Diabetic I/R+ $\boldsymbol{O}$. persica & $112.25 \pm 5.17$ & $2.09 \pm 0.11$ & $1.14 \pm 0.07$ & $59.55 \pm 6.08$ & $8.63 \pm 0.89$ \\
\hline
\end{tabular}

*Significantly different from sham and $\mathrm{I} / \mathrm{R}+O$. persica groups at $\mathrm{p}<0.05$;

${ }^{\dagger}$ Significantly different from Diabetic sham and Diabetic $\mathrm{I} / \mathrm{R}+O$. persica groups at $\mathrm{p}<0.05$.

\section{Discussion}

This study was under taken with the objective of exploring evaluate the effect of $O$. persica in the pretreatment of I/R induced renal injuries in diabetic rats. The transient discontinuation of renal blood flow is encountered in many clinical situations including partial nephrectomy, kidney transplantation, renal artery angioplasty, aortic aneurysm surgery, and certain urological operations $^{19}$. This temporary discontinuation causes renal I/R damage which results in decreased renal blood flow and glomerular filtration and increased urine output characterized by natriuresis and impaired concentrating ability. Acute renal failure produced by ischemia and reflow is histopathologically characterized by extensive tubular damage such as tubular cell necrosis, signs of tubular obstruction with cell debris and glomerular injury ${ }^{20}$.

Diabetics are at a higher risk of an ischemic condition caused by the decreased blood supply. With increasing the duration and severity of ischemia, greater the cell damage can develop, with a predisposition to a spectrum of reperfusion-associated pathologies, collectively called reperfusion injury ${ }^{1}$. Since type 2 diabetes, causes organ dysfunction and increases the sensitivity of organs to damages ${ }^{21}$.

The antioxidant activities of different extracts and fractions of the $O$. persica were evaluated using beta-carotene bleaching and lipid peroxidation methods ${ }^{22}$. The results showed that $O$. persica extract exhibited strong antioxidant activity. Currently, the consumption of natural antidiabetic agents that occur in some higher plants and in different parts of them, have risen up regarding the side effects of synthetic ones ${ }^{23}$. Antidiabetic properties of $O$. persica have been confirmed in several in vitro and in vivo studies ${ }^{12,24,25}$. Antidiabetic effect of the $O$. persica extract was studied on streptozotocin-induced diabetic rats. Animals received a daily oral dose of $O$. persica extract for 3 weeks. The extract produced a dose-dependent decrease in the blood glucose level. These results indicate that $O$. persica has a strong antidiabetic action and can decrease blood glucose levels ${ }^{24}$. Administration of $O$. persica extract $(100,200$ and $300 \mathrm{mg} / \mathrm{kg})$ in diabetic rats for 6 and 14 days and at $300 \mathrm{mg} / \mathrm{kg}$ for 3 days also significantly decreased glucose serum levels ${ }^{25}$. Recently, antidiabetic properties of aqueous extract of $O$. persica $(400 \mathrm{mg} /$ $\mathrm{kg}$ ) on the blood glucose, insulin and histopathology of pancreas of streptozotocin-induced diabetic rats were confirmed ${ }^{11}$.

In this study, diabetic rats showed a renal dysfunction in the form of a significant increase in the serum creatinine and urea levels. This finding is considered as an indicator of deteriorated renal function ${ }^{26}$. In addition, the results of the study confirmed that the combination of renal ischemia with diabetes raised the renal dysfunction more than did diabetes alone suggesting a significant impairment, thus, of the glomerular function ${ }^{27}$. In addition, both normal and diabetic rats exposed to renal $\mathrm{I} / \mathrm{R}$ exhibited an increase of oxidative stress products including tissue MDA. The depletion of the antioxidant enzymes pool was demonstrated by the declined activity in kidney tissues of SOD and CAT. This notion was confirmed by Jitendra et al. ${ }^{1}$ who emphasized that the oxidative stress is implicated both in the complications of type 2 diabetes and renal $\mathrm{I} / \mathrm{R}$ and that the combined oxidative stress from these two sources may, thus, increase the total level of ROS. These deleterious effects associated with renal $\mathrm{I} / \mathrm{R}$ were improved by the treatment with $O$. persica. These results suggest that $O$. persica extract pretreatment could have a positive effect to reduce renal $\mathrm{I} / \mathrm{R}$ injury in diabetic rats. 


\section{Conclusions}

Diabetes provoked an exaggerated renal ischemiareperfusion injury in Streptozotocin treated rats. O. persica treatment is effective in attenuating acute $\mathrm{I} / \mathrm{R}$-induced renal damage in diabetic rats.

\section{References}

1. Jitendra DV, Navin RS, Yagnik SB, Nurudin PJ. Exaggerated liver injury induced by renal ischemia reperfusion in diabetes: Effect of exenatide. Saudi J Gastroenterol. 2010 Jul-Sep; 16:174-80. PMID: 20616412.

2. Nakazawa J, Isshiki K, Sugimoto T, Araki S, Kume S, Yokomaku Y, Chin-Kanasaki M, Sakaguchi M, Koya D, Haneda M, Kashiwagi A, Uzu T. Renoprotective effects of asialoerythropoietin in diabetic mice against ischaemia-reperfusion-induced acute kidney injury. Nephrology. 2010 Feb;15:93-101. PMID: 20377776.

3. Erdogan H, Fadillioglu E, Yagmurca M, Ucar M, Irmak MK. Protein oxidation and lipid peroxidation after renal ischemia-reperfusion injury: Protective effects of erdosteine and $\mathrm{N}$-acetylcysteine. Urol Res. 2006 Feb;34:41-6. PMID: 16429300.

4. Noiri E, Nakao A, Uchida K, Tsukahara H, Ohno M, Fujita T, Brodsky S, Goligorsky MS. Oxidative and nitrosative stress in acute renal ischemia. Am J Physiol Renal Physiol. 2001 Nov;281:948-57. PMID: 11592952.

5. Ysebaert DK, De Greef KE, De Beuf A, Van Rompay AR, Vercauteren S, Persy VP, De Broe ME. T cells as mediators in renal ischemia/reperfusion injury. Kidney Int. 2004 Aug;66:491-6. PMID: 15253695.

6. Altunoluk B, Soylemez H, Oguz F, Turkmen E, Fadillioglu E. An Angiotensin-converting enzyme inhibitor, zofenopril, prevents renal ischemia/reperfusion injury in rats. Ann Clin Lab Sci. 2006;36:32632. PMID: 16951275.

7. Matés JM, Perez-Gomez C, Nunez de Castro I. Antioxidant enzymes and human diseases. Clin Biochem. 1999;32:595-603. PMID: 10638941 .

8. Rhee MH, Park HJ, Cho JY. Salicornia herbaceae: botanical, chemical and pharmacological review of halophyte marsh plant. J Med Plants Res. 2009;3(8):548-55.

9. Asghari G, Nourallahi H, Havaie SA, Isa L. Antimicrobial activity of otostegia persica Boiss extracts. Res Pharm Sci. 2006;1:53-8.

10. Yassa N, Sharififar F, Shafiee A. Otostegia persica as a source of natural antioxidants. Pharm Biol. 2005;43(1):33-8.

11. Akbarzadeh S, Bazzi P, Daneshi A, Nabipour I, Pourkhalili K, Mohebbi GH, Sartavi K, Abdi MR, Mirzaei M Bargahi A. Antidiabetic effect of Otostegia persica extract on diabetic rats. J Med Plants Res. 2012;6(16):3176-80.

12. Ayatollahi SAM, Kobarfard F, Asgarpanah J, Choudhary MI Antiglycation activity of otostegia persica (Burm) boiss. Afr J Biotechnol. 2010;9(24):3645-8.

13. Masiello P, Broca C, Gross R, Roye M, Manteghetti M, HillaireBuys D, Novelli M, Ribes G. Experimental NIDDM: development of a new model in adult rats administered Streptozotocin and Nicotinamide. Diabetes. 1998 Feb;47:224-9. PMID: 9519717.

14. Preuss HG, Jarrell ST, Scheckenbach R, Lieberman S, Anderson RA. Comparative effects of chromium vanadium and Gymnema sylvestre on sugar-induced blood pressure elevations in SHR. J Am Coll Nutr. 1998 Apr;17:116-23.
15. Marklund SL. Regulation by cytokines of extracellular superoxide dismutase and other superoxide dismutase isoenzymes in fibroblasts. J Biol Chem. 1992 Apr;267:6696-701. PMID: 1551878.

16. Aebi H. Catalase in vitro. Method Enzymol. 1984;105:121-6.

17. Guevara I, Iwanejko J, Dembinska-Kiec A. Determination of nitrite/ nitrate in human biological material by the simple Griess reaction. Clin Chim Acta. 1998 Jun;274:177-88. PMID: 9694586.

18. Wei H, Frenkel K. Relationship of oxidative events and DNA oxidation in SENCAR mice to in vivo promoting activity of phorbol ester-type tumor promoters. Carcinogenesis. 1993 Jun;14:1195201. PMID: 8508507.

19. Paller MS. Acute renal failure: controversies, clinical trials, and future directions. Semin Nephrol. 1998 Sep;18:482-9. PMID: 9754600

20. Chatterjee PK, Cuzzocrea S, Thiemermann C. Inhibitors of poly (ADP-ribose) synthetase protect rat proximal tubular cells against oxidant stress. Kidney Int. 1999 Sep;56:973-84. PMID: 10469365.

21. Gabr MM, Sherif IO, Ali SI, Mohamed HE. Renal ischemia/ reperfusion injury in type $2 \mathrm{DM}$ : possible role of proinflammatory cytokines, apoptosis, and nitric oxide. Eur J Sci Res. 2010;47:63248.

22. Sadeghi Z, Akaberi M, Valizadeh J: Otostegia persica (Lamiaceae). A review on its ethnopharmacology, phytochemistry, and pharmacology. Avicenna J Phytomed. 2014;4(2):79-88.

23. Asgarpanah J, Mohammadi Motamed S. A review on phytochemistry and pharmacology of Otostegia persica (Burm.f.) Boiss. J Med Plants. 2013;12(47):8-18.

24. Ebrahimpoor MR, Khaksar Z, Noorafshan A. Anti-diabetic effect of orally administered Otostegiapersica extract on streptozotocin diabetic rats. Comp Clin Pathol. 2011;20:523-5.

25. Hedayati M, poureboli I, Poureboli B, Dabiri S, Javadi A. Effect of methanolic extract of Otostegia persica on serum levels of glucose and lipids in type I diabetic male rats. Koomesh. 2010;12(4):43542.

26. Kuhad A, Chopra K. Attenuation of diabetic nephropathy by tocotrienol: involvement of NF-kB signaling pathway. Life Sci. 2009 Feb;84(9-10):296-301. PMID: 19162042.

27. Tawfik MK. Renoprotective activity of telmisartan versus pioglitazone on ischemia/reperfusion induced renal damage in diabetic rats. Eur Rev Med Pharmacol Sci. 2012 May;16(5):600-9. PMID: 22774400.

\section{Correspondence:}

Mohammad Ashrafzadeh Takhtfooladi

Young Researchers and Elites Club, Science and Research Branch Islamic Azad University, Tehran Iran

Phone: +98 9121590428

Fax: +98 2144629353

dr_ashrafzadeh@yahoo.com

Received: Feb 15, 2016

Review: Apr 12, 2016

Accepted: May 18, 2016

Conflict of interest: none

Financial source: none

${ }^{1}$ Research performed at Department of Clinical Science, Science and Research Branch, Islamic Azad University, Tehran, Iran. 